\title{
Genetic testing and early diagnosis and intervention: boon or burden?
}

\author{
Elizabeth R Hepburn IBVM Queensland Bioethics Centre, Brisbane, Australia
}

\begin{abstract}
The possibility of early diagnosis and intervention is radically changed by the advent of genetic testing. The recent report of the Nuffield Council on Bioethics is timely and helpful. I have suggested, that not only the severity of the disability indicated by genetic information, and the accuracy of the data, ought to govern the approach to the implementation of screening for genetic disorders. In addition, assessment of the value of the information to those involved should be considered. The efficacy of the available therapeutic measures, combined with the prognostic data are important indices of the value of the information. These measures fall into three categories and thus indicate that three different courses of intervention may be appropriate. Three approaches to diagnosis and intervention are then outlined, drawing on the experience of various clinical initiatives.
\end{abstract}

\section{Introduction}

The notion that early diagnosis and intervention is important therapeutically is almost an article of faith in medicine. The advent of genetic testing raises the possibility of a re-definition of "early". The prospect of disease and disability can be detected reliably and early in the case of phenylketonuria (PKU) and testing in the first week of life has become routine. The Human Genome Project promises the identification of all inherited genetic abnormalities prior to birth. Whilst growing use of prenatal testing might work against the interests of the child, as the practice acquires the characteristics of quality control and we demand "perfect" offspring; the potential for fetal therapy may also work against the interests of the mother, who may be required to submit to invasive procedures in the service of the baby. However, genetic mapping will permit diagnosis and intervention earlier than during fetal development. ${ }^{1}$ It is possible to identify the carriers of genetic defects and warn them of the risk of abnormalities, such as TaySachs disease. In this case "early" is not merely

\section{Key words}

Prenatal diagnosis; genetic screening; ethics. prenatal, but preconception. Moreover, the best strategy will often be behavioural rather than strictly medical.

Diagnostic investigation raises questions about the status of the fetus, the rights of parents with respect to children, our understanding of normality/ abnormality and whose interests are really served by our increasing application of diagnostic testing. ${ }^{2}$ It puts into question the claim that early intervention is always for the best. It may be that genetic fingerprinting will be both boon and burden. We need to ask ourselves for whom, and when, and under what circumstances, genetic screening will provide more benefit than harm. Our answers to such questions are ultimately answers to the question of what it means to be human.

Proposals to institute massive screening programmes for genetic defects ought to be viewed with caution. The recent Nuffield Council on Bioethics recommendations on genetic screening (1993), whilst timely and cautious, are like earlier authoritative statements, ${ }^{3}$ rather too broad to guide policy and practice. It seems to me that there are critical differences between the tests for disease, both in terms of their timing and specificity, and in terms of the nature of the disease itself, which influence the way in which we ought to deal with issues of policy. However, the Nuffield report suggests principles which ought to govern policy and practice, namely: that screening be voluntary and the results treated as confidential; that counselling and education be available to potential participants, and that the use of genetic test results by employers and health insurers be restricted and conditioned by the interests of the employee or client. I will show that three scenarios, differentiated by the nature of the intervention possible following diagnosis, require three different approaches, which are consistent with the Nuffield principles.

\section{Illness and abnormality}

The prospect of reducing the frequency of congenital abnormalities seems to be a logical extension of prenatal care and in keeping with the promotion of health and wellbeing. The advent of these techniques 
raises questions too. The very definition of "normal" comes into sharp relief and the decision as to what to do when an abnormality is detected becomes a more frequent occurrence. As Hannah Arendt asked so pointedly: "Who has the right to determine who shall inhabit the world?"4 And how will those appointed to this task make their decisions?

Rothman $^{5}$ has pointed out that disability is a social construct. In countries where sex selection is permitted the rate of male births far exceeds female births and it is probably true that in many societies girls and women are so socially disadvantaged that female gender may be construed as a disability. Indeed, Fletcher $^{6}$ sees the prospect of widespread sex selection serving to relegate female sex to the category of a genetic disorder. Rothman is concerned that the availability of genetic testing will diminish our tolerance of difference and that ever-increasing quality control will be demanded. The emergence of a new form of tort - litigation in which either children hold their parents responsible for their "wrongful" life, ${ }^{7}$ or in which parents sue doctors for wrongful birth, ${ }^{8}$ supports Rothman's claim.

A side-effect of a growing intolerance of congenital variation construed as abnormality may be to exacerbate the disadvantage already suffered by those members of our society who are seen as disabled. The extension of testing carries a very clear message of rejection to such people. The availability of a diagnostic test creates a sense of protection from abnormality and parental disappointment and rejection may be heightened as a result. Before we embark on further development or institute screening procedures, we need to explore, as a society, what we understand by notions of normality and how far we are prepared to tolerate deviation from such a socially determined norm.

Those who have experienced prenatal testing, especially in the form of ultrasound, testify to the heightened awareness of the developing entity as a child. The tests themselves can strengthen the bond between parents and child at an early stage in the pregnancy. Indeed, Fletcher ${ }^{8}$ thinks that progress in fetal therapy will tend to elevate the status of the fetus. Yet the purpose of the diagnostic test is to permit a decision to intervene either therapeutically, or in some cases, to end the life of a fetus for whom therapy is not possible, or to prepare for the birth of a disabled child. The decision to abort requires distancing, especially for the mother, precisely at a time when relatedness has just been emphasised. ${ }^{9}$ Parents, and mothers in particular, are faced with a conflict exacerbated by the technology itself. Just at the moment of recognition of the embryo as a living entity, it may be suggested that this life be ended.

\section{Whose rights?}

The prospect of two physicians attending pregnant women, but with differing expertise and concerns, raises the possibility of mutually exclusive courses of therapeutic action being proposed. The argument which might then arise would be like an extension of the current pro-choice/pro-life argument. Very often the debate is couched in terms of rights and this being so, it is important, as many have pointed out, to establish the moral status of the fetus. Is the fetus an entity which can properly be said to have rights or interests?

Progress in both neonatology and fetal therapy

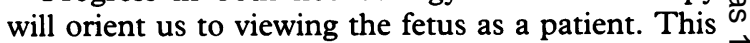
new category of patient may be seen as having a right $\vec{\circ}$ to health care, apparently conferring the status of $\overrightarrow{\vec{\omega}}$ person on the fetus. Certainly in some jurisdictions $\underset{\sigma}{\omega}$ in the United States the fetus is seen as having rights to protection from harm. There have been cases in $\overparen{D}$ which action has been brought against pregnant $N$ women who were exposing their offspring to terato- ? genic agents by taking various drugs. There is also $\vec{\circ}$ legislation permitting discrimination against women in the workplace, in order to avoid possible fetal injury through exposure to teratogenic hazards. ${ }^{10} \vec{\nabla}$ Yet if the fetus carries an abnormality not amenable to treatment, although not lethal, will the fetus be disenfranchised as a patient? If so, it seems the assumed personal status of the fetus is contingent on ? normality and we would face again the dilemmas which anti-discriminatory legislation, such as the US People with Disabilities Act, seeks to eliminate. On the other hand, some might claim that euthanasia in the form of abortion, is the right of the disabled $\stackrel{\varnothing}{\varnothing}$ fetus, indeed, is in that patient's interests.

\section{Duty of care}

The crux of the argument is whether it is actually the fetus on whom rights are conferred or to whom $\overparen{\Phi}$ interests are ascribed, or if such attribution is contin- $\frac{\sigma}{7}$ gent on the decision to protect the life of the child. Traditionally the life of the fetus was defended in virtue of its potential to become a full member of the human community. ${ }^{11}$ Now it seems that for some 음 the decision as to whether the pregnancy will be $D$ supported to term determines whether the developing child will be protected from harm. Thus many argue that although abortion is justifiable, the decision to bring a child to birth implies a duty of ${ }_{N}^{N}$ care, even prenatally. The same people campaign $\omega$ both for the right to abortion and for the right of the unborn child to protection from prenatal assault ore injury. In a sense, rights are not conferred on the fetus but are claimed on behalf of the future child, $\stackrel{+}{+}$ the born person the fetus has the potential to $\frac{0}{0}$ become. My own view is that these claims should be $\frac{\overrightarrow{\mathbb{C}}}{\mathrm{D}}$ honoured from conception, that we ought not $\frac{\mathrm{O}}{\mathbb{Q}}$ choose to end the life of even a potential person. $\stackrel{\mathbb{Q}}{\varrho}$ Exploration of these issues, along with those on which I have chosen to focus, must be part of theo public debate about early diagnosis and genetico응 testing, since abortion will be an option when a grave condition is detected. Greater accuracy in diagnosis 
may result in a higher incidence of medically indicated abortion and polarisation of the abortion issue will not serve us well in the long term.

\section{Testing and investing}

In modern Western societies it is often relatively simple to encourage people to seek diagnostic testing. Culturally, the ascendancy of science has engendered a growing desire to exert control over events and to reduce uncertainty. In some situations diagnostic testing can provide a means to both ends. Yet the value of the knowledge gleaned from diagnostic tests is questionable. In a highly entertaining essay Clifton Meador, ${ }^{12}$ recently made the observation that the last well person in the world is going to be enmeshed in so many defensive practices s/he will scarcely have time to enjoy being well. There is a serious point to this, namely the evaluation of whether particular items of information are desirable. It reflects our deepest convictions and commitments. It is not true that information is neutral, that our response to it is what determines its value and meaning. There is such a thing as "bad news"; early diagnosis of an invariably fatal condition before the onset of a disease such as amyotrophic lateral sclerosis (ALS or Lou Gehrig's Disease), is just one example. Where ignorance is bliss, it may indeed, be folly to be wise.

All of this takes on another dimension when the information is not about oneself but a dependent other with no capacity for autonomous action or decision. In such circumstances, it is normal to make a decision which minimises risk to that individual. A risk we assess as worthwhile on our own account, may often seem too great to undertake on behalf of another. Expectant parents are in a very vulnerable position. Society encourages risk minimisation and control. Not to protect one's offspring by every means available amounts to dereliction of duty and added to that is the natural alternation of hope and apprehension about the birth of a new child. In most cases, parents are dependent on expert advice and may feel quite incompetent to make choices between treatments. Many will seek maximal protection and risk reduction, any test available will be seen as not only a boon, but a necessity. In such a setting, the likely market for prenatal diagnostic tests is enormous.

Diagnosis is the first step in establishing treatment options, and identification of genetic abnormalities may occur soon after birth, during pregnancy, at conception or prior to conception. However powerful and accurate genetic screening tests become, there will always be a margin of error and some genetic abnormalities will not be detected until after birth. Identification of a genetic abnormality during pregnancy permits immediate therapeutic intervention; a decision can be taken to support or terminate the pregnancy. Should all means to promote life be pursued or does serious disability influence the way in which we evaluate therapeutic intervention? Prospective parents who carry abnormal genes could select healthy early embryos using in vitro fertilisation (IVF) procedures which would permit inspection of the early embryo before transfer. A problem which then arises, is what is to be done with the genetically abnormal embryo. Nevertheless, intervention at the time of conception obviates decisions about whether to maintain and complete a pregnancy and how to treat the disabled child after birth.

The diagnostic information itself indicates three different sorts of intervention. First, there may be the identification of an inherited or congenital abnormality which is easily detected after birth, and simple and cheap to treat, an example would be phenylketonuria (PKU). Second, there may be the identification of a gene which always causes a disease for which there is no treatment and which is always fatal, for instance, Tay-Sachs disease. Third, it may be possible to identify a gene which predisposes the carrier to a life-threatening disease, for which there is treatment but no cure, such as, for example, a breast cancer gene (BRCA1). ${ }^{13}$ In each case, the response to the information is modified by the likely outcome and the efficacy of available treatment. It is, therefore, reasonable to assume that the approach to screening for each category of disease should be different. Of the three, the third is presumably going to be the most common once the human genome is mapped. In these circumstances knowledge of one's genetic complement may be boon or burden.

\section{Cost-effective}

The detection of phenylketonuria $(\mathrm{PKU})^{1+15}$ through routine screening of urine of newborns is a good example of the way in which early diagnosis may be critical. The genetic disorder is easily and cheaply detected and it is a relatively simple matter to protect the newborn from exposure to the potentially damaging phenylalanine. The diet prescribed is free of this amino acid. For PKU both detection and treatment are relatively straightforward. Further, the special diet provides protection against the expression of the disease. That is, in the case of PKU both hereditary and modifiable environmental factors influence outcome. In fact, routine screening for PKU occurs in most Western health care settings. The test is clearly in the best interests not only of the infant, but also of the parents and society, since there is a cost-effective way of treating the disease.

The possibility of detecting the breast cancer gene (BRCA1) has given rise to suggestions that women in families known to be susceptible to early onset breast cancer be screened for the gene. ${ }^{16}$ Of those carrying the gene some 80 per cent are expected to develop disease. ${ }^{17}$ So 20 per cent, for some reason, carry the gene but do not ever show signs of disease. 
Just as with PKU, the expression of disease is not dependent on the presence of the gene alone. Unlike PKU though, treatment for breast cancer is difficult, costly, risky and often unsuccessful. Treatment options range from radical, bilateral mastectomy as a teenager or participation in a Tamoxifen trial, to careful monitoring and conventional treatment if and when disease appears. Even if the first option is taken, there is no guarantee of freedom from cancer. In either case, knowledge of the presence of the gene is likely to heighten not only awareness, but apprehension. In such families awareness is already present. The genetic test merely confirms the suspicion. Possession of the gene does not sentence one to disease, nor does its absence guarantee freedom from disease. Yet the way in which we speak of genetic testing implies that the test is definitive: accurate and absolute. Until a means of replacing or blocking the action of the BRCA1 gene is available, the value of having the information is equivocal.

The capacity to detect the BRCA1 gene raises further questions. Who should have access to the information? At what age should girls be informed of the test, be tested and be informed of their genetic status? Should those men and women carrying the gene commit themselves to childlessness in order to stem the passage of the gene to future generations? Should these people be advised to enter in vitro fertilisation (IVF) programmes, so that disease-free embryos could be selected prior to implantation? These questions attend tests for every identifiable inherited disease. It is probably true that each of us carries genetic portenders of our ultimate cause of death. When the human genome is mapped how will we determine the limits of normality and who should be tested? The dream of a population free of genetic defect will not be achieved simply by knowledge of the genome, it will require the implementation of a social policy which can justify the elimination of unwanted genes.

At present, the elimination of unwanted genes will depend on restriction of reproduction. Death of the actual weakest would be supplanted by exclusion of the potential weakest. The human population could be managed in the same way as animal herds. In fact, a group of Hassidic Jews in New York has adopted just such a strategy in dealing with Tay-Sachs disease. Marriages are arranged so that the disease is not passed on. In a relatively small, closed community such a scheme is possible, but for the wider community it seems more problematic. However, in Montreal there has been some success in screening young people for particular diseases. The programme has operated through schools, and has been supported by a sound and effective educational programme. Groups known to be at risk for Tay-Sachs disease, $\beta$-thalassaemia and cystic fibrosis have been offered genetic testing during their late adolescent years. A follow-up study showed that eight years after testing, participants were glad to have the infor- mation and were in favour of making genetic testing available. ${ }^{18}$ Informing likely carriers of abnormal $\overline{0}$. genes permits them to make informed and respon- $?$ sible choices about their future reproductive $\vec{\Rightarrow}$ behaviour.

The vision of a world free of inherited disease is $\frac{}{0}$ presented by commercial interests, as not only desir- $\frac{\bar{c}}{\underline{\underline{D}}}$ able, but possible. Medical expenditure would be $\overparen{\mathbb{D}}$ channelled from care facilities to drug companies and laboratories. In prospect we will be beguiled by $\infty$ the thought that prevention is better than cure. In $\vec{O}$ reality, we will have lost sight of the fact that life is a $\vec{\overrightarrow{ }}$ terminal condition and that health care, whatever $\stackrel{\omega}{\omega}$ the cause of disease, is an on-going expense. It

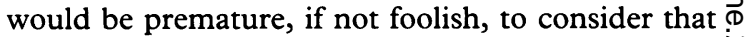
the removal of all inherited diseases would reduce $N$ overall health care expenditure. I am not suggesting ? that we do not proceed with genetic and fetal $\vec{\circ}$ research, or that such knowledge is not helpful, I G am simply warning that it may not bring all the 9 advantages it promises. Further, it is clear that we $\vec{\overrightarrow{ }}$ need to find ways of using diagnostic procedures and 0 information well, so that the dignity of the individual is honoured, and the value of the intervention process is tangible to the person concerned.

\section{Using diagnostic information well}

I have suggested that the realisation of the dream of a population free of inherited defects would depend $\stackrel{\mathbb{D}}{\mathscr{Q}}$ as much on public policy as on biomedical know- $\overrightarrow{\vec{P}}$ ledge. Clearly, the strength of the Hassidic com- $\frac{9}{\exists}$ munity policy is that it is democratically determined by a majority, and there is consent to the practice by all involved. The individuals are treated within such an arrangement as ends in themselves, they are self- $\overline{0}$ determining in the matter. In this situation familiar- $\dot{\sigma}$ ity with the disease, access to accurate information and the apparent consent of all involved removes $\delta$ some of the concerns associated with notions of selective breeding in human populations. Those 의 making the policy of restriction are themselves the $D$ subjects of the constraints, constraints which are viewed collectively as essential to the health, and $\bar{N}$ even survival, of the community. The group wanted s to remain both homogeneous and healthy. There $\tilde{O}$ were two distinct and strong incentives to implement $\underset{\omega}{N}$ such a policy.

Secondly, the disease itself is not only fatal butco horribly debilitating through its progress. There is no treatment for the disease. No one could view $\stackrel{\mathcal{C}}{?}$ Tay-Sachs disease as manageable or tolerable. Its 7 patterns of passage from one generation to another $\frac{\vec{\Phi}}{\mathbb{D}}$ are well understood. There is no way of dealing with $\stackrel{?}{\mathscr{P}}$ the disease other than to eradicate it. The alter- $\stackrel{\mathbb{Q}}{\mathscr{Q}}$ natives to arranged marriages, barring the use of new reproductive technologies, would be to accept the status quo or to enforce childlessness for many, if not most, thus ensuring the decline of the community as an entity. 
Thirdly, it is possible to see this strategy as shortterm: within a few generations the disease could be eradicated from the community. The social change is instituted in the interests of the life of the community as an on-going entity. It is not envisaged that the social change will be permanent. In the case of PKU, identification, treatment and control were all simply and cheaply achieved. There was no stigma attached to having the disease and it was in the patient's best interests to establish PKU status and initiate treatment as soon as possible. Further, as evidenced in Montreal too, when the screening programme is accompanied by sound and effective public health education, those tested regard the information as beneficial and access to tests as a service.

It seems to me that there are a number of lessons we can draw from the Hassidic experience and successful screening programmes for congenital diseases such as PKU, to employ within the wider community.

- First, genetic tests should only be used routinely to prevent the occurrence of diseases which are universally regarded as causing intolerable suffering or to detect those for which there is a simple and cheap cure or preventative measure.

- Second, genetic screening should be restricted to those diseases which are well understood, that is, the certainty of the information should provide a sufficient basis from which an individual can act, and for which adequate genetic counselling is available.

- Third, as a public health measure, educational programmes should focus on those inherited diseases for which there is reasonable hope of prevention, and eventually of eradication, by voluntary agreement of those who would undergo screening, to halt the passage of the genes involved.

- Finally, it is critical that all such programmes are backed by sound public health education, and that there is not only broad public approval of the policy, but also the opportunity for individuals not to be disadvantaged if they elect not to participate in screening programmes.

All of these considerations are further modified by the accuracy of the genetic test. Not all tests are conclusive. Issues of probability in relation to diagnosis should be a prominent aspect of both educational programmes and the advice given in counselling. Often press releases from research laboratories give the impression that the results of testing are unequivocal and absolutely accurate. In view of the tendency of those engaged in this work to be not only enthusiastic but perhaps too optimistic about the outcome of testing it would seem wise to separate the educational and counselling services from the clinical setting. A precaution observed by many in vitro fertilisation (IVF) clinics is the separation of the functions of organ procurement and replacement in organ transplant procedures. It is hoped that such an arrangement will minimise possible conflicts of interest and protect both prospective parents and children from exploitation.

I have concerned myself here only with prenatal testing for disability and disease and primarily with those diseases known to have a genetic basis. The question of enhancing the genotype of offspring ${ }^{19}$ is important and raises another set of issues. The question is likely to attract attention in places with either private or mixed funding for health care. In countries in which health care is largely publicly funded it is likely that taxpayers would baulk at footing the bill to indulge the desires of parents for say, blonde, athletic offspring. The view that health care is a human right and its provision a community responsibility, will put limits on what is seen as legitimate health care. ${ }^{20}$

In contrast, it would seem that in the United States the "free-market" ethos, which sees medicine as a commodity, will spawn practitioners keen to corner a new market niche: the "designer child" will be available. Arguments relating to this issue must be cast in as wide a context as possible, examining some of the issues already mentioned, such as rejection when expectations of a perfect child are unmet; lost opportunities of resources allocated to seeking a "perfect" baby rather than, perhaps, health care of the parents and the less "perfect" siblings of such a child, and the societal implications of rejecting the hybrid, happy children many of us have been, despite our imperfections. For this reason, the recommendation of the Nuffield Council on Bioethics for further work by the Department of Health (UK) in establishing criteria and review processes for the practice of genetic screening, is to be welcomed.

\section{Conclusion}

I have suggested that since the results of genetic testing differ greatly in terms of therapeutic value, screening policies should reflect these differences. In situations in which the tests are known to be accurate and the appropriate treatment is simple and cheap, screening programmes accompanied by sound and effective educational programmes seem to be appropriate public health measures. In cases where the transmission of the defective gene will result in the birth of offspring with serious and untreatable disabilities, it is suggested that comprehensive educational programmes targeted at specific groups be conducted in late adolescence (prior to childbearing), and genetic testing and counselling be made available. This puts those affected in possession of the information they require in order to make informed reproductive choices. The last and most problematic group is that for which genetic factors indicate a predisposition to a specific disease for which there is no adequate treatment. It is inappropriate to embark on wholesale screening in such circumstances and it is even questionable whether such 
information will be construed as boon or burden by those affected. The experience of people living with AIDS $^{21}$ and those who have had breast cancer, ${ }^{18}$ suggests that the most helpful thing which medicine has to offer is honest information, and sensitive and respectful assistance with decision-making. Not to tell patients the "bad news" ultimately works against the interests of all concerned.

\section{Acknowledgements}

This paper was prepared during my time as a Visiting Scholar at the McGill Centre for Medicine, Ethics and Law. I am grateful to all who made me welcome there and to the Loreto sisters for their generous support of this time of study. The Queensland Bioethics Centre is at 18 Clarence Street, South Brisbane, Australia, 4101 and serves the five Catholic dioceses of Queensland. Sr Regis Mary Dunne RSM, the founding Director, helped to clarify several technical points.

Elizabeth R Hepburn, IBVM, BSc(Hons), $M A, P h D$, is Director of the Queensland Bioethics Centre, Brisbane, Australia.

\section{References and notes}

1 The terms "baby", "child", and "fetus" may all be used of the one entity. The function of technical language is to create distance. I think it is helpful to retain the relational language, of "child" and "baby", in determining how best we can deal with conflicts of interest when they arise. It also underscores my own view that the fetus is due the protection owed to a person and that the fetus is best regarded as a person and a patient.

2 It also raises questions about the rights of parents to seek modification of the genotype to enhance capacities. Here, I deal only with issues associated with the use of prenatal testing for disabilities.

3 Wilson J, Junger G. Principles and practice of screening for disease. Geneva: World Health Organisation, public health papers No 34, 1968.

4 Arendt $\mathrm{H}$ cited by Hubbard R. Eugenics: new tools, old ideas. In: Baruch EH, D'Adamo AF, Seager J, eds. Embryos, ethics and women's rights. New York: Harrington Press, 1988: 225-36.

5 Rothman B. Reproductive technology and the commodification of life. In: Baruch EH, D'Adamo AF, Seager J, eds. Embryos, ethics and women's rights. New York: Harrington Press, 1988: 95-100.

6 Fletcher JC. Ethical issues in genetic screening and antenatal diagnosis. Clinical Obstetrics and Gynecology 1981 ; 24: 1151-68.
7 It should be noted that the majority of jurisdictions do not at present recognise the right of a child to complain about having been born. Shaw M. The potential plain- of? tiff: preconception and prenatal torts. In: Milunsky $A, \vec{\Rightarrow}$ Annas GJ, eds. Genetics and the law II. New York: 오ำ Plenum, 1980: 225-32.

8 Dickens B. Wrongful birth and life, wrongful death $\frac{\mathrm{\sigma}}{}$ before birth and wrongful law. In: McLean SAM, ed. Legal issues in human reproduction. Aldershot: Gower, 1989: 80-112.

9 Hubbard R. Eugenics: new tools, old ideas. See reference 6: 225-36.

10 Daniels CR. At women's expense. Cambridge, MA: Harvard University Press, 1993.

11 Noonan JT. An almost absolute value in history. In: Noonan JT, ed. The morality of abortion. Cambridge, MA: Harvard University Press, 1970.

12 Meador CK. The last well person. New England fournal $N$ of Medicine 1994; 330: 440-1.

13 This gene had not been identified when the report was prepared so these possibilities were not considered.

$14 \mathrm{PKU}$ is inherited through two recessive genes, one from $\mathrm{O}$ each parent.

15 Similar points could be made with respect to a screening programme for $\mathrm{Rh}$-negative factor in maternal blood. Testing is routine. Treatment is straightforward (either, immunisation of Rh-negative mothers or exchange transfusion of blood for the baby) and effec- ? tive, if undertaken in utero or in the first few hours of life.

16 Batt S. Patient no more. Charlottetown, Prince Edward Island: Gynergy, 1994.

17 Figures vary, 80 per cent is an estimate only. Ford D, Easton DF, Bishop DT, Narod SA, Goldgar DE. Risks of cancer in BRCA1-mutation carriers. Lancet 1994; 343: $692-6$, indicates 87 per cent penetrance of the breast cancer gene by age 70 . Easton D. Breast-ovarian cancer families and the BRCA1 gene. Lancet 1994; 343: 711 , indicates carriers have a 50 per cent risk of breast cancer by age 50,70 per cent by age 70 . Easton DF, Bishop DT, Ford D, Crockford GP. Genetic linkage analysis in familial breast and ovarian cancer: results from 214 families. American fournal of Human Genetics 1993; 52: 678-701 indicates carriers have a cumulative risk of 59 per cent by age 50,82 per cent by 70 .

18 Zeesman S, Clow C, Cartier L, Scriber C. A private view of heterozygosity: eight year follow-up study on carriers of the Tay-Sachs gene detected by high school $\mathrm{N}$ screening in Montreal. American fournal of Human Genetics 1984; 18: 769-78.

19 The technical capacity to enhance human genotypes is $\mathrm{N}$ not currently available.

20 See Leary V. The right to health in international human rights law. Health and Human Rights 1994; 1: 24-57.

21 Shilts R. And the band played on. New York: Bantam, 1988. 